Annual Review of Applied Linguistics (2005) 25, 112-130. Printed in the USA.

Copyright @ 2005 Cambridge University Press 0267-1905/05 \$12.00

\title{
6. LANGUAGE LEARNING STRATEGY INSTRUCTION: CURRENT ISSUES AND RESEARCH
}

\author{
Anna Uhl Chamot
}

This chapter begins with definitions and an overview of methods used to identify learners' strategies, then summarizes what we have learned from the large number of descriptive studies of strategies reported by language learners. Research on language learning strategies has a history of only about thirty years, and much of this history has been sporadic. The 1980s and early 1990s were a period of substantial research on language learning strategies, much of it descriptive. This period was followed by an apparent loss of interest in language learning strategies, judging by limited reported research and few related conference presentations. Recently, however, a number of new investigations have reinvigorated the field. The focus of the chapter is on the evolution of research on language learning strategy intervention studies, the issues that have emerged from this research, and metacognitive models that can be useful in the language classroom. The discussion concludes by setting out directions for future research.

\section{Definition and Importance of Strategies}

Learning strategies are procedures that facilitate a learning task. Strategies are most often conscious and goal-driven, especially in the beginning stages of tackling an unfamiliar language task. Once a learning strategy becomes familiar through repeated use, it may be used with some automaticity, but most learners will, if required, be able to call the strategy to conscious awareness. Learning strategies are important in second language learning and teaching for two major reasons. First, by examining the strategies used by second language learners during the language learning process, we gain insights into the metacognitive, cognitive, social, and affective processes involved in language learning. The second reason supporting research into language learning strategies is that less successful language learners can be taught new strategies, thus helping them become better language learners (Grenfell \& Harris, 1999). Numerous descriptive studies have addressed the goal of understanding the range and type of learning strategies used by good language learners and the differences in learning strategy use between more and less effective 
learners. However, until relatively recently there have been fewer studies focusing on the second goal of trying to teach language learning strategies in classroom settings.

Learning strategies are sensitive to the learning context and to the learner's internal processing preferences. If learners perceive, for example, that a task like vocabulary learning requires correct matching of a new word to its definition within a specified period of time (as in a test), they will likely decide to use a memorization strategy. Their choice of which memorization strategy to use will depend on their understanding of their own learning processes and on which strategies have been successful in the past (Hsiao, 2004). A different task, such as being able to discuss the theme of a short story will require strategies different from memorization-such as making inferences about the author's intended meaning and applying the learner's prior knowledge about the topic. The interpretation of a language learning task is closely related to the goals advocated within each learner's cultural context, for a learning strategy valued in one culture may be deemed inappropriate in another (Olivares-Cuhat, 2002; Wharton, 2000). A particular learning strategy can help a learner in a certain context achieve learning goals that the learner deems important, whereas other learning strategies may not be useful for that learning goal.

\section{Methods for Identifying Learners' Strategies}

Learning strategies are identified through various self-report procedures. Although self-report is always subject to error, no better way has yet been devised for identifying learners' mental processes and techniques for completing a learning task. Learning strategies are for the most part unobservable, though some may be associated with an observable behavior. For example, a student listening to new information may use selective attention (unobservable) to focus on the main ideas and might then decide to take notes (observable) on these main ideas. The only way to find out whether students are using selective attention during a listening comprehension task is to ask them. Mere observation has proven unsatisfactory in identifying learners' strategies (Cohen, 1998; O’Malley \& Chamot, 1990; Rubin, 1975; Wenden, 1991).

Self-reports have been conducted through retrospective interviews, stimulated recall interviews, questionnaires, written diaries and journals, and thinkaloud protocols concurrent with a learning task. Each of these methods has limitations, but at the present time they remain the only way to generate insights into the unobservable mental learning strategies of learners.

\section{Interviews}

In retrospective interviews, learners are prompted to recall a recently completed learning task and describe what they did to complete it (see Macaro, 2001). A stimulated recall interview is more likely to accurately reveal students' actual learning strategies because it is conducted immediately after a learning task. The actual task is videotaped, and the interviewer then plays back the videotape, 


\section{ANNA UHL CHAMOT}

pausing as necessary, asking the student to describe his or her thoughts at specific moments during the learning task.

\section{Questionnaires}

The most frequently used method for identifying students' learning strategies is through questionnaires. Some studies have developed questionnaires based on tasks that students have just completed (see Chamot \& El-Dinary, 1999; Fan, 2003; Goh, 2002a; Kojic-Sabo \& Lightbown, 1999; Ozeki, 2000; Rubin \& Thompson, 1994; Weaver \& Cohen, 1997). Most descriptive studies, however, have relied on a questionnaire developed by Oxford (1990), the Strategy Inventory for Language Learning (SILL). This instrument has been used extensively to collect data on large numbers of language learners (see Cohen, Weaver, \& Li, 1998; Olivares-Cuhat, 2002; Oxford, 1990; 1996; Oxford \& Burry-Stock, 1995; Wharton, 2000). The SILL is a standardized measure with versions for English as a second language (ESL) students and students of a variety of other languages, and as such can be used to collect and analyze information about large numbers of students. It has also been used in studies to correlate strategy use with variables such as learning styles, gender, proficiency level, culture, and task (Bedell \& Oxford, 1996; Bruen, 2001; Green \& Oxford, 1995; Oxford, Cho, Leung, \& Kim, 2004; Nyikos \& Oxford, 1993; Oxford \& Burry-Stock, 1995; Wharton, 2000). Oxford and her colleague are currently developing a task-based questionnaire to complement the SILL (Oxford et al., 2004).

\section{Diaries and Journals}

Written diaries and journals have also been used to identify language learners' strategies. In these, learners write personal observations about their own learning experiences and the ways in which they attempted to solve language problems (see, for example, Carson \& Longhini, 2002). Rubin (2003) suggests using diaries for instructional purposes to help students develop metacognitive awareness of their own learning processes and strategies. An interesting variant on the diary study was recently conducted by Takeuchi (2003), who examined published books and essays by Japanese good language learners of various languages and analyzed each author for evidence of learning strategy use included in their descriptions of their foreign language learning histories.

\section{Think-Aloud Protocols}

A think-aloud protocol can be used for individual interviews in which the learner is given a target language task and asked to describe his or her thoughts while working on it. The interviewer may prompt with open-ended questions such as, "What are you thinking right now? Why did you stop and start over?" Recordings of think-aloud interviews are then analyzed for evidence of learning strategies. The rich insights into language-learning strategies provided through think-aloud protocols tend to reveal online processing, rather than metacognitive aspects of planning or 
evaluating (see Chamot \& Keatley, 2003; Cohen et al., 1998; O'Malley \& Chamot, 1990).

Although self-report may be inaccurate if learners do not report truthfully or cannot remember their thinking, it is still the only way available to us to develop some understanding of learners' mental processing. As Grenfell and Harris have pointed out: "It is not easy to get inside the 'black box' of the human brain and find out what is going on there. We work with what we can get, which, despite the limitations, provides food for thought" (1999, p. 54)

\section{Identification of Language Learning Strategies}

The language learning strategies identified through these self-report methods have identified characteristics of good language learners and compared the strategies of more- and less-effective language learners. Such studies have been important in identifying and classifying strategies used by language learners and understanding how strategies are actually used in the learning process. This information has in turn guided instructional investigations that have sought to teach learning strategies to language learners and to measure relationships between strategy use and language proficiency, metacognition, motivation, and self-efficacy.

Language learning strategies research began in the 1970s with the seminal work of Joan Rubin, who, like Stern (1975), suggested that a model of "the good language learner" could be constructed by looking at special strategies used by successful L2 students (Rubin, 1975). Other researchers followed with descriptions of learner characteristics and strategic techniques associated with effective second and foreign language learning (Naiman, Fröhlich, Stern, \& Todesco, 1978/1996; O'Malley, \& Chamot, 1990). More recently, Takeuchi (2003) identified the characteristics of Japanese good language learners through their biographies. Taken together, these studies identified the good language learner as one who is a mentally active learner, monitors language comprehension and production, practices communicating in the language, makes use of prior linguistic and general knowledge, uses various memorization techniques, and asks questions for clarification.

Later studies comparing more and less effective language students have revealed a recurring finding that less successful learners do use learning strategies, sometimes even as frequently as more successful peers, but that their strategies are used differently (Chamot \& El-Dinary, 1999; Khaldieh, 2000; Vandergrift, 1997a, 1997b). A recent study by Vandergrift (2003a) compared the listening comprehension strategies of more- and less-skilled Canadian seventh-grade students of French. Students listened to several French texts and were prompted to think aloud during the process. The more skilled listeners used more metacognitive strategies, especially comprehension monitoring, than did their less skilled peers. In addition, more skilled listeners engaged in questioning for clarification, whereas the less skilled used more translation. Graham (2004) investigated the attitudes toward learning French of upper secondary English students and found that the less successful students did not seem to be aware of the potential role of learning strategies in improving their language performance. 
These studies have confirmed that good language learners are skilled at matching strategies to the task they were working on, whereas less successful language learners apparently do not have the metacognitive knowledge about task requirements needed to select appropriate strategies. This trend is apparent with children in foreign language immersion classrooms, secondary school ESL and foreign language students, and adult language learners (Chamot \& El-Dinary, 1999; Chamot \& Keatley, 2003). In addition, more proficient L2 learners use sequences of strategies to complete a task effectively (Chamot, Barnhardt, El-Dinary, \& Robbins, 1999; Goh, 2002b; Oxford et al., 2004).

The large number of descriptive studies of language learning strategies reveals suggestive differences between more and less successful learners. Can less successful language learners be taught to use the learning strategies that contribute to the achievements of their more successful peers? Proponents of language learning strategy instruction point to the substantial body of research in first language contexts that supports the explicit teaching of learning strategies for academic achievement in other content areas (De La Paz \& Graham, 2002; Graham \& Harris, 2000; National Reading Panel, 2000; Pressley, 2000). Because learning strategy instruction has been shown to improve performance on first language tasks such as vocabulary learning, reading comprehension, and writing, it is likely that it could prove equally helpful for language learners in these and other L2 tasks such as listening and speaking, modalities not investigated in the first language literature.

\section{Classroom Research on Language Learning Strategy Instruction}

Although the majority of language learning strategy investigations have been simply descriptive, a number of researchers have conducted studies in which language learning strategies have been taught to students. This section briefly reviews representative studies carried out in language classroom settings in which teachers and/or researchers have provided more or less explicit instruction on learning strategies.

The relatively small number of instructional language learning strategy studies may be due, in part, to the inherent difficulties in conducting classroom research. Ideally, an intervention study should have randomly assigned participants to either a control or an experimental/treatment group. Instruction in each group should be identical except for the presence or absence of the innovation being studied. Participants should be pre- and posttested on valid and reliable instruments that identify not only knowledge about and use of the innovation (e.g., learning strategies), but also measure other factors deemed important in learning, such as achievement/proficiency, motivation, attitude, and/or self-efficacy. It is rarely possible to adequately control for all of these possible variables in any natural classroom setting.

In one of the first experimental studies of language learning strategies instruction, high school ESL students were taught how to apply learning strategies to 
three different types of tasks, and their performance was compared to that of students in a nonstrategies control group (O'Malley \& Chamot, 1990). This study was conducted with 75 high school ESL students randomly assigned to experimental or control groups. Students were pretested on three types of language tasksvocabulary, listening comprehension, and speaking from prepared notes-but not on their use of learning strategies. The experimental group students were taught various strategies for the same types of tasks over a two week period. The instruction was provided by the researchers, all of whom had ESL teaching experience. Students were posttested on the same types of tasks, but did not report on their use of learning strategies. The main conclusions of this first language learning strategies experimental study were as follows:

- Vocabulary learning strategies were effective only for students who had not already developed alternative effective strategies.

- Listening comprehension improved for students instructed in learning strategies on texts that were accessible, not on those that were too difficult and/or for which students lacked relevant prior knowledge.

- Oral reports (presented from written notes) given by strategy-instructed students were judged to be significantly more comprehensible and organized than those of control group students.

- Explicit learning strategy instruction embedded within the language syllabus appeared to be effective.

These conclusions support some of the major tenets proposed in current language learning strategy instructional models, including the importance of not overlooking students' current learning strategies, careful choice of tasks for practicing learning strategies, and providing explicit and embedded learning strategy instruction. Although this study of L2 learning strategies was successful in showing that second language learners could improve their language performance by using instructed learning strategies, limitations of the study are clear. These interrelated limitations include the study's short duration (only two weeks) and absence of follow-up; the lack of a measure of students' use of learning strategies prior and subsequent to instruction; and the fact that researchers rather than the normal classroom teachers provided the instruction. Many of these limitations have been addressed in subsequent intervention studies regarding the effects of language learning strategy instruction for listening comprehension, speaking and oral communication, reading comprehension, vocabulary learning, and writing strategies.

\section{Listening Comprehension Strategies Studies}

Several studies have sought to help language learners use strategies to increase their comprehension of oral texts. For example, Ross and Rost (1991) first identified the listening comprehension strategies used by higher proficiency students and then successfully taught these to lower proficiency students. Another study of listening comprehension was conducted over an entire academic year (Thompson \& Rubin, 1996). Students receiving strategy instruction showed significant improvement on a video comprehension posttest compared to the students in the 
control group. In addition, students in the strategies group demonstrated metacognitive awareness through their ability to select and manage the strategies that would help them comprehend the videos.

More recently, Ozeki (2000) followed the example of Ross and Rost (1991) by first identifying the listening strategies students already used as a basis for selecting strategies to be taught. In this case, however, the strategies to be taught were those students had reported that they used least frequently. Although intact classes of students of English in a Japanese women's college were used for the treatment and control groups, randomization was achieved by the assignment of students to class sections alphabetically by surname. Strategy instruction was provided in the treatment class during 12 ninety-minute classes focusing on listening comprehension distributed over a 20 -week semester. The sequence of instruction was as follows: a preparation stage in which students were explicitly taught a new strategy and earlier strategies were reviewed; and a lesson stage in which students practiced the strategies with listening comprehension tasks. Pretest and posttest scores were compared to evaluate the effects of learning strategy instruction. Improvement in the treatment group was noted in the following dimensions: development of listening comprehension ability; increased use of learning strategies (including some not explicitly taught); positive attitudes towards strategy instruction; transfer of strategies to new tasks; and durability of strategy use after the completion of strategy instruction.

Carrier (2003) taught listening comprehension strategies to a small group of high school ESL students. This exploratory study focused on academic listening tasks during six weeks of instruction. The strategies included both bottom-up and top-down approaches to listening. The teacher modeled and defined the strategies, then provided practice opportunities for the students. Actual strategies taught included selective attention to various aspects of the text and note-taking. Pre- and posttests on both discrete and overall listening comprehension showed that students had significantly improved both aspects of listening comprehension.

In another recent study of listening comprehension strategies, Vandergrift (2003b) undertook a study of French as a second language university students in which he sought to raise awareness of the listening process through tasks designed to develop effective listening strategies. After being told the topic of the listening task, students completed a column on a worksheet in which they listed (in French and/or in English) their predictions about information they might hear. Then they listened to the text, checking off predictions and vocabulary they had anticipated and adding new information. Next, they worked in pairs to compare and discuss what they had understood. A second listening to the text allowed students to fill in additional information comprehended, and this was followed by a class discussion in which students shared the strategies they had used to comprehend the text. After a third listening, students wrote a personal reflection on what they had learned about their own listening processes and what strategies they might use in future to improve listening comprehension. Similar procedures were followed for an additional listening task. Students' written reflections revealed positive reactions to the 
strategies, increased motivation, and understanding of their own thinking processes during listening tasks.

\section{Oral Communication Strategies Studies}

Perhaps the most challenging language modality for learning strategy instruction is oral communication, for deliberate use of a strategy could restrict the flow of natural speech. Presentational speaking, rather than interactive speaking, has been the focus of several studies (see Cohen, 1998; O'Malley \& Chamot, 1990). In interactive speaking, researchers have looked at communication strategies with some reservations because of doubts that using a communication strategy (such as using a gesture when the needed word or phrase is not known) actually can lead to learning (Cohen, 1998; Macaro, 2001, Nakatani, in press).

A comprehensive study of speaking strategies investigated the impact of strategies-based instruction on college foreign language students taught by their regular instructors over during 10 weeks of instruction (Cohen, et al., 1998; Cohen, 1998). The intervention groups received instruction in learning strategies for speaking tasks. Students were pre- and post-tested on speaking tasks and on the Strategy Inventory for Language Learning (SILL) (Oxford, 1990). In addition, a sample of students provided think-aloud data as they were completing task checklists. The results indicated that integrating strategies instruction into the language course was beneficial to students, although the relationship of reported strategy use to performance was complex.

In a recent study of oral communication strategies, Nakatani (in press) compared pre- and posttest oral communication test results of students receiving metacognitive awareness-raising and a control group. The subjects were students at a women's college in Japan who had completed six years of prior English study. The strategy training group was taught communication strategies that could help students learn more of the language such as asking for clarification, checking for comprehension, and paraphrasing, rather than communication strategies without a direct influence on learning, such as abandoning a message or reverting to the L1. Results showed that students taught to use strategies showed significant improvement on oral proficiency tests.

\section{$\underline{\text { Reading Comprehension Strategies Studies }}$}

Although reading strategy interventions in first language contexts have been plentiful (see, for example, Pressley, 2000), this modality has attracted less attention among language learning instruction researchers. A recent study investigating different approaches to literacy development in high school ESL students with low literacy in their native language included a learning strategies instructional component (Chamot \& Keatley, 2003). A curriculum of scripted literacy lessons included explicit language learning strategy instruction for reading comprehension, including sounding out, selective attention, summarizing, cooperation, predicting, brainstorming of prior knowledge, visualization, and making inferences. Six of the 


\section{ANNA UHL CHAMOT}

teachers provided initial strategy instruction in the students' L1, then asked students to use the same strategies when reading in English. The remaining eight teachers attempted to teach the strategies only in English. Data from classroom observations and from end-of-year individual think-aloud interviews in which students described (in L1) the strategies they were using to read an unfamiliar text in English showed the following:

- Teachers found it easier to teach strategies in the native language.

- Some students reported using the instructed strategies during the think-aloud interviews.

- Students who were more able to verbalize their thinking processes (in L1) displayed greater comprehension of the L2 text than those unable to describe their thoughts.

Another recent study of reading comprehension investigated the effects of strategy instruction on lower and higher proficiency levels and also assessed students' continuing use of strategies after the conclusion of instruction (Ikeda \& Takeuchi, 2003). Participants were 210 students of English at a Japanese university. Students were divided into two groups according to their English language proficiency; each group was then further divided into an experimental and a control group. The experimental groups received explicit reading strategy instruction integrated into their regular class over an eight-week period. Instructed strategies included making inferences, using selective attention, using imagery, and summarizing. Pre- and posttests (carried out at different intervals) consisted of reading English texts, then completing a survey in Japanese of strategies used during the reading task. The results indicated that the strategy instruction affected the frequency of students' use of the strategies only for the high proficiency level group. The authors' interpretation was that most of the strategies taught involved top-down processing, but that what the low proficiency group probably needed was a focus on bottom-up processing strategies. Students were tested after instruction and then again three months and five months later to see if they continued to use the instructed strategies. An encouraging finding was that students retained their use of learning strategies for reading five months after the conclusion of instruction.

A recently completed study built on Ikeda and Takeuchi's (2003) work to further explore the effects of task difficulty in reading comprehension and use of strategies (Oxford et al., 2004). ESL college students completed two reading tasks (one easy, one difficult); these scores were used to determine whether students were eithermore- or less-proficient readers, and also completed questionnaires about their strategy use for the two readings. For the easy reading, there was little difference in strategy use between more and less proficient readers. However, for the more difficult reading, less proficient students actually used more strategies than their more proficient peers. The authors attributed this finding to the fact that the "difficult" reading was actually not much of a challenge for the higher proficiency students, and thus they did not need to use many learning strategies. 
$\underline{\text { Vocabulary Strategies Studies }}$

Learning new vocabulary in a second language is a continuing process rather than a single event. Beginning level students often believe that vocabulary learning is all that is involved in second language acquisition and may focus their efforts and strategies on this single component. Deep processing strategies such as association have been found more effective in vocabulary retention than rote repetition strategies (see Cohen \& Aphek, 1981; Hulstijn, 1997; O’Malley \& Chamot, 1990; Schmitt, 2000).

In a recent descriptive vocabulary study of Hong Kong university students learning English, Fan (2003) identified important implications for strategy instruction. For example, when students perceived that a strategy was useful, they used it more often than strategies they did not perceive as useful. Even so, students with higher vocabulary proficiency used strategies significantly more often even when they did not perceive them as useful. This finding suggests that students might use more learning strategies if teachers were to first convince students of their usefulness.

This approach was taken in a series of case studies in England in which researchers worked closely with five secondary teachers of modern languages as teachers experimented with learning strategy instruction for a variety of tasks (Grenfell \& Harris, 1999). Three of the teachers focused on teaching memorization strategies for vocabulary. The strategy instruction was generally explicit and students' metacognition was developed through a variety of consciousness-raising activities. Most students were willing to adopt the new strategies, though they rarely used them in combination. Performance on tests indicated that the memorization strategies had been helpful for many in learning new vocabulary.

\section{Writing Strategies Studies}

Writing in a second language is arguably the most difficult of the modalities in which to achieve communicative competence. Beginning level students struggle with finding the words they need and remembering grammatical conventions, whereas more advanced students find it difficult to link their ideas with coherence and to produce appropriate target language discourse. Given these difficulties, instruction in writing strategies could be beneficial for second language learners.

A study of writing strategies instruction was recently conducted in England with six classes of secondary students of French (Macaro, 2001). In this Oxford Writing Project, classes were randomly assigned to control or experimental groups. Pre- and posttests included questionnaires, writing tasks, and think-aloud interviews during a French writing task. Students in the experimental groups received about five months of instruction on a variety of writing strategies that included the metacognitive strategies of advance preparation, monitoring, and evaluating. At posttest, experimental groups had made significant gains in the grammatical accuracy of their writing. In addition, they reported a change in their approach to writing, 
becoming less reliant on the teacher, more selective in their use of the dictionary, and more careful about their written work.

Another recent writing strategies study explored the effects of translation (a learning strategy) from the L1 on the quality of essays written in French by university students of French (Cohen \& Brooks-Carson, 2001). Students were given prompts in the target language, then instructed to either write directly in French or to write the essay first in their L1, then translate it to French. Strategy checklists completed after students wrote the essays showed that students writing directly in French reported less thinking in English during the composing process and their essays were also rated higher than those who had gone through the translation process.

\section{Methodological and Practical Issues in Learning Strategy Instruction}

Although we can be cautiously optimistic about the effectiveness of learning strategy instruction, given that it has been well established in first language contexts and shows promise in second language learning, a number of issues still remain concerning specific teaching approaches. These include the language of strategy instruction, the practicality of integrating strategy instruction into the regular language class, and the use of metacognitive models to classify learning strategies for instructional purposes. Although these issues are far from resolved, some recent studies that have addressed them are briefly described in this section.

\section{Language of Strategy Instruction}

This issue is particular to teaching learning strategies to language learners. In first language contexts, strategies are taught through a language medium in which students are proficient, but in second or foreign language contexts, this is not necessarily so. Beginning level students, in particular, do not have the L2 proficiency to understand explanations of why and how to use learning strategies, yet postponing learning strategy instruction until intermediate or advanced level courses deprives beginners of tools that could enhance language learning and increase motivation for further study. It is probably not possible to avoid using the first language during strategy instruction for beginning to low intermediate level students (Macaro, 2001). Suggestions have been made to initially teach the learning strategies in the students' native language, assuming it is the same for all students and that the teacher knows the language; alternatively, teachers have been urged to give the strategy a target language name, explain how to use it in simple language, and model the strategy repeatedly (Chamot et al., 1999).

Some recent studies have used a combination of the native and target languages for strategy instruction. In an investigation of strategy instruction by secondary French and German teachers in London, some materials were in English (especially those used by students for planning and evaluating their own work), whereas checklists, descriptions of strategies, and strategy activities were written in the target language, simplified as needed (Grenfell \& Harris, 1999). In a study of 
Japanese college students learning English as a foreign language, questionnaires, journal prompts, and self-evaluation checklists were written in "simple" English, but students could respond in Japanese; actual strategy instruction and review was conducted in English (Ozeki, 2000). In Chamot and Keatley's (2003) ESL literacy study, bilingual teachers were able to first teach the learning strategies in students' native language, then had them use the same strategies in English for similar reading tasks in English. Teachers providing instruction in English alone encountered difficulties in teaching learning strategies because of the low level of students' English proficiency, and most then abandoned the attempt to teach strategies. From these few studies, it seems clear that the issue of language of instruction in teaching language learning strategies is far from resolved, and may need to be addressed as a context-specific factor.

\section{$\underline{\text { Explicit and Integrated Learning Strategy Instruction }}$}

Explicit instruction includes the development of students' awareness of their strategies, teacher modeling of strategic thinking, identifying the strategies by name, providing opportunities for practice and self-evaluation. Researchers in both L1 and L2 contexts agree that explicit instruction is far more effective than simply asking students to use one or more strategies and also fosters metacognition, students' ability to understand their own thinking and learning processes (Anderson, 2002, in press; Carrier, 2003; Chamot, 2004, 2005; Chamot et al., 1999; Cohen, 1998, 2003; Goh, 2002b; Graham \& Harris, 2000; National Reading Panel, 2000; O'Malley \& Chamot, 1990; Oxford \& Leaver, 1996; Pressley, 2000; Shen, 2003).

Less agreement is found on whether strategy instruction should be integrated into and taught concurrently with the language course, or whether to provide a separate "how to learn" course independent of the language course. Although all of the studies reviewed here have included strategy instruction as part of the regular language class, it has been argued that strategies taught in a language class are less likely to transfer to other tasks and that it may not be practical to prepare all language teachers to teach strategies (Gu, 1996). Clearly, expertise in teaching language learning strategies must be integrated into pre- and in-service preparation if teachers are to provide it to their L2 students.

\section{Impact of Task and Learner Context}

As noted earlier, learning strategies are directed toward particular tasks that can vary in both obvious and subtle ways. Tasks differ depending on whether the context is a second language or foreign language setting and whether the learner's goal is to acquire social or academic language or both (Chamot, 2004; Cohen, 2003; Cummins, 2000; Oxford et al., 2004). Differences in strategy use also vary according to proficiency level. Takeuchi's (2003) multiple case studies of learner journals found that learners reported shifting their use of strategies as they advanced to higher proficiency levels. Similarly, a recent reading study found that perceived difficulty of the task affected use of learning strategies, which were used on more challenging tasks (Oxford et al., 2004). 
The learner's goals, the context of the learning situation, and the cultural values of the learner's society will also influence choice and acceptability of language learning strategies. For example, in a culture that prizes individual competition and has organized its educational system around competitive tasks, successful language learners may prefer strategies that allow them to work alone rather than social strategies that call for collaboration with others.

Two SILL studies illustrate the learning strategy preferences reported by students in different cultural contexts. A study of ethnically Chinese, bilingual Singaporean university students studying a foreign language (French or Japanese) found that students reported a preference for social strategies as well as a disinclination to use affective strategies (Wharton, 2000). Another study examined the language learning strategies of students in a university advanced Spanish writing class and compared achievement on a writing sample between those students speaking Spanish as a first or heritage language and those learning Spanish as a foreign language (Olivares-Cuhat, 2002). As expected, students with a Spanish language background were graded higher on their writing samples than the other students, but they also showed a greater preference for affective and memory strategies, and these latter were highly correlated with writing achievement. Preliminary findings of a current study of learning strategies used by university students of less commonly taught languages indicate that both heritage speakers of Arabic and students of Arabic as a foreign language share many of the same challenges and consequent learning strategies for learning Modern Standard Arabic (MSA), but also demonstrate differences (Keatley, Chamot, Spokane, \& Greenstreet, 2004). For instance, heritage speakers reported using metacognitive strategies to overcome interference from their Arabic dialects when they attempted to speak MSA, but, unlike the foreign language students, had no difficulty in discriminating Arabic sounds and hence did not report any learning strategies for listening comprehension.

The implications for teaching are that language teachers need to find out what learning strategies students already use for different tasks. An open discussion of reasons why students use the strategies they identify can help teachers understand cultural and contextual factors that may be influencing their students. This can lead to clarification of task demands where there is a mismatch with students' current learning strategies. By understanding the task more clearly, students will likely be more motivated to try new strategies to complete it.

\section{$\underline{\text { Metacognitive Models }}$}

The development of students' metacognition, or their ability to understand and regulate their own thinking and learning, has been urged by a number of learning strategy researchers (Anderson, 2002; Chamot et al., 1999; National Capital Language Resource Center, 2003; Rubin, 2001; Wenden, 2000). Metacognition is believed to involve both declarative (self-knowledge, world knowledge, task knowledge, strategy knowledge) and procedural knowledge (planning for learning, monitoring a learning task while it is in progress, and evaluating learning once a task 
has been completed; Chamot, 1994). Evidence that language learners actually engage in metacognitive knowledge and processes is reported in most of the research on language learning strategies, both descriptive and instructional. Even young children in language immersion classrooms can often describe their thinking processes, demonstrating metacognitive awareness in their ability to describe their own thinking (Chamot, 1999).

There are several current models for strategy identification, development, and instruction that emphasize metacognition. My colleagues and I have proposed a metacognitive model for learning strategy instruction that includes four recursive (rather than sequential) processes: planning, monitoring, problem-solving, and evaluating (Chamot, 1994; Chamot et al., 1999). In this model, teachers select learning strategies to teach depending on the point in a learning task where students need the most help. For example, students who do not seem to realize that a learning task is not progressing well can be taught to monitor their comprehension, production, or recall so that they can identify difficulties and select problem-solving strategies to address the difficulties. Rubin (2001) equates self-management with self-regulation as defined in the first language learning strategies literature (see, for example, Pressley, 1995). Her learner self-management model includes five metacognitive strategies: plan, monitor, evaluate, problem-solve, and implement. The model is partly linear and partly recursive, and interacts with learners' knowledge and beliefs. Anderson (2002) proposes a five-stage interactive process that includes planning, selecting and using learning strategies, monitoring strategy use, orchestrating various strategies, and evaluating the strategies used. In addition to describing this metacognitive model, he also suggests how teachers can use it to teach students how to become better language learners.

Similarly, the National Capital Language Resource Center (NCLRC; 2003) has proposed a metacognitive model in which the learner's problem-solving goals are at the center of the circular model. Surrounding these learner goals are the metacognitive strategies of planning, monitoring, managing learning, and evaluating language learning and learning strategy effectiveness. Task-based learning strategies comprise the outer circle of the model and are grouped into four categories: use what you know, use your imagination, use your organizational skills, and use a variety of resources. Teacher resource guides developed for elementary immersion classrooms (NCLRC, 2003), high school foreign language classrooms (NCLRC, 2004a), and higher education foreign language classrooms (NCLRC, 2004b) apply this model to classroom instruction.

\section{Developing Teacher Expertise}

These metacognitive models of language learning strategies can serve an important instructional goal for learning strategy instruction in second and foreign language classrooms by offering a way to think about language learning strategies from the perspective of the learner and the teacher, rather than from that of the researcher (as has characterized the claims of different strategy classification systems, for example, Hsiao \& Oxford, 2002). Comprehensive classification 
schemes of learner strategies are needed to describe the information derived from descriptive studies that seek to chart the subtle permutations and often slippery definitions of learners' self-reported strategies. However, these extended and complex definitions may be less useful in the language classroom where the teacher is trying to help students become more strategic as they cope with actual learning tasks rather than the hypothesized learning tasks proposed in the many questionnaires and interviews designed to identify strategies that language learners claim to use.

\section{Directions for Future Research}

The study of language learning strategies will continue to develop as second language acquisition researchers seek to understand different learner characteristics and the complex cognitive, social, and affective processes involved in processing language input and using the language for a variety of purposes. Likewise, language educators and methodologists will continue their quest for more effective instructional approaches, and, with the increasing emphasis on learner-centered instruction and learner empowerment in all areas of education, instruction in learning strategies will assume a greater role in teacher preparation and curriculum design.

First, rigorous intervention studies would provide information about the effects of learning strategy instruction on achievement and language proficiency. Such studies need to be conducted with a variety of language students, including children in foreign language immersion and nonimmersion programs, school-aged students in bilingual and second language programs, older students with differing educational levels in their native language, and students in different learning contexts around the world.

A second area for future research is in the development of language teacher expertise for integrating learning strategies into classroom instruction. The evaluation of different models for teacher preparation in learning strategies instruction could lead to refining and improving current models. In addition, studies need to be undertaken to identify the relationship of effective learning strategy instruction to teacher characteristics such as teaching approach, attitude and teacher beliefs, amount and type of preservice and/or in-service preparation in learning strategy instruction, and years of teaching experience and length of time teaching learning strategies - it might be that effective learning strategy instruction is closely tied to specific individual teacher characteristics and experiences.

It is important that learning strategies research continue, both in these and other directions, for only through a better understanding of the learning and teaching process can more language learners achieve the level of success that currently characterizes only a small proportion of all students studying a foreign or second language around the world. Strategy instruction can contribute to development of learner mastery and autonomy and increased teacher expertise, but additional research in specific language learning contexts is essential to realizing its potential to enhance second language acquisition and instruction. 


\section{REFERENCES}

Anderson, N. J. (2002). The role of metacognition in second language teaching and learning. ERIC Digest, April 2002. Washington, DC: Center for Applied Linguistics.

Anderson, N. J. (in press). L2 learning strategies. In E. Hinkel (Ed.), Handbook of research in second language teaching and learning. Mahwah, NJ: Erlbaum.

Bedell, D. A., \& Oxford, R. L. (1996). Cross-cultural comparisons of language learning strategies in the People's Republic of China and other countries. In R. L. Oxford (Ed.), Language learning strategies around the world: Crosscultural perspectives (pp. 47-60). Honolulu, HI: University of Hawaii Press.

Bruen, J. (2001). Strategies for success: Profiling the effective learner of German. Foreign Language Annals, 34(3), 216-225.

Carrier, K. A. (2003). Improving high school English language learners' second language listening through strategy instruction. Bilingual Research Journal, 27, 383-408.

Carson, J. G., \& Longhini, A. (2002). Focusing on learning styles and strategies: A diary study in an immersion setting. Language Learning, 52(2), 401-438.

Chamot, A. U. (1994). A model for learning strategy instruction in the foreign language classroom. In J. E. Alatis (Ed.), Georgetown University Round Table on Languages and Linguistics 1994 (pp. 323-336). Washington, DC: Georgetown University Press.

Chamot, A. U. (1999). How children in language immersion programs use learning strategies. In M. A. Kassen (Ed.), Language learners of tomorrow: Process and promise! (pp. 29-59). Lincolnwood, IL: National Textbook Company.

Chamot, A. U. (2004). Issues in language learning strategy research and teaching. Electronic Journal of Foreign language Teaching, 1(1), 12-25.

Chamot, A. U. (2005). The Cognitive Academic Language Learning Approach (CALLA): An update. In P. A. Richard-Amato \& M. A. Snow (Eds.), Academic success for English language learners: Strategies for $\mathrm{K}-12$ mainstream teachers (pp. 87-101). White Plains, NY: Longman.

Chamot, A. U., Barnhardt, S., El-Dinary, P. B., \& Robbins, J. (1999). The learning strategies handbook. White Plains, NY: Addison Wesley Longman.

Chamot, A. U., \& El-Dinary, P. B. (1999). Children's learning strategies in immersion classrooms. The Modern Language Journal, 83, 3, 319-341.

Chamot, A. U., \& Keatley, C. W. (2003). Learning strategies of adolescent lowliteracy Hispanic ESL students. Paper presented at the 2003 Annual Meeting of the American Educational Research Association, Chicago, IL.

Cohen, A. D. (1998). Strategies in learning and using a second language. London: Longman.

Cohen, A. D. (2003). The learner's side of foreign language learning: Where do style, strategies, and tasks meet? International Review of Applied Linguistics, 41, 279-291.

Cohen, A. D., \& Aphek, E. (1981). Easifying second language learning. Studies in Second Language Learning, 3, 221-36. 
Cohen, A. D., \& Brooks-Carson, A. (2001). Research on direct versus translated writing: Students' strategies and their results. Modern Language Journal, $85(2), 169-188$.

Cohen, A. D., Weaver, S., \& Li, T-Y. (1998). The impact of strategies-based instruction on speaking a foreign language. In A. D. Cohen, Strategies in learning and using a second language (pp. 107-156). London: Longman.

Cummins, J. (2000). Language, power, and pedagogy: Bilingual children in the crossfire. Clevedon, England: Multilingual Matters.

De La Paz, S., \& Graham, S. (2002). Explicitly teaching strategies, skills, and knowledge: Writing instruction in middle school classrooms. Journal of Educational Psychology, 94(4), 687-698.

Fan, M. Y. (2003). Frequency of use, perceived usefulness, and actual usefulness of second language vocabulary strategies: A study of Hong Kong learners. Modern Language Journal, 87(2), 222-241.

Goh, C. C. M. (2002a). Learner's self-reports on comprehension and learning strategies for listening. Asian Journal of English Language Teaching, 12, 46-68 [Special issue on learning and teaching English in the Chinese context].

Goh, C. C. M. (2002b). Exploring listening comprehension tactics and their interaction patterns. System, 30, 185-206.

Graham, S. J. (2004). Giving up on modern foreign languages? Students' perceptions of learning French. Modern Language Journal, 33(2), 171-191.

Graham, S., \& Harris, K. R. (2000). The role of self-regulation and transcription skills in writing and writing development. Educational Psychologist, 35, 312.

Green, J. M., \& Oxford, R. (1995). A closer look at learning strategies, L2 proficiency, and gender. TESOL Quarterly, 29(2), 261-297.

Grenfell, M., \& Harris, V. (1999). Modern languages and learning strategies: In theory and practice. London: Routledge.

Gu, P. Y. (1996). Robin Hood in SLA: What has the learning strategy researcher taught us? Asian Journal of English Language Teaching, 6, 1-29.

Hsiao, T.-Y. (2004). Testing a social psychological model of strategy use with students of English as a foreign language. Psychological Reports, 95, 10591071.

Hsiao, T.-Y., \& Oxford, R. L. (2002). Comparing theories of language learning strategies: A confirmatory factor analysis. Modern Language Journal, 86(3), 368-383.

Hulstijn, J. H. (1997). Mnemonic methods in foreign language vocabulary learning. In J. Coady \& T. Huckin (Eds.), Second language vocabulary acquisition (pp. 203-224). Cambridge: Cambridge University Press.

Ikeda, M., \& Takeuchi, O. (2003). Can strategy instruction help EFL learners to improve their reading ability?: An empirical study. JACET Bulletin, 37, 4960.

Keatley, C., Chamot, A. U., Spokane, A., \& Greenstreet, S. (2004). Learning strategies of students of Arabic. The Language Resource, 8 (4). Retrieved from http://www.nclrc.org/nectfl04ls.pdf 
Khaldieh, S. A. (2000). Learning strategies and writing processes of proficient vs. less-proficient learners of Arabic. Foreign Language Annals, 33(5), 522533.

Kojic-Sabo, I., \& Lightbown, P. M. (1999). Students' approaches to vocabulary learning and their relationship to success. Modern Language Journal, 83(2), 176-192.

Macaro, E. (2001). Learning strategies in foreign and second language classrooms. London: Continuum.

Naiman, N., Fröhlich, M., Stern, H. H., \& Todesco, A. (1978/1996). The good language learner. Clevedon, England: Multilingual Matters. (Original work published 1978.)

Nakatani, Y. (in press). The effects of awareness-raising training on oral communication strategy use. Modern Language Journal, 89(1).

National Capital Language Resource Center (NCLRC). (2003). Elementary immersion learning strategies resource guide. Washington, DC: National Capital Language Resource Center.

National Capital Language Resource Center (NCLRC). (2004a). The secondary education learning strategies resource guide. Washington, DC: National Capital Language Resource Center.

National Capital Language Resource Center (NCLRC). (2004b). The post-secondary education learning strategies resource guide. Washington, DC: National Capital Language Resource Center.

National Reading Panel (2000). Report of the National Reading Panel: Teaching children to read. Retrieved from http:/www.nichd.nih.gov/publications/nrp/smallbook.htm

Nyikos, M., \& Oxford, R. L. (1993). A factor analytic study of language learning strategy use: Interpretations from information-processing theory and social psychology. Modern Language Journal, 77, 11-22.

O'Malley, J. M., \& Chamot, A. U. (1990). Learning strategies in second language acquisition. Cambridge, UK: Cambridge University Press.

Olivares-Cuhat, G. (2002). Learning strategies and achievement in the Spanish writing classroom: A case study. Foreign Language Annals, 35(5), 561-570.

Oxford, R. L. (1990). Language learning strategies: What every teacher should know. New York: Newbury House.

Oxford, R. L. (1996). (Ed.) Language learning strategies around the world: Crosscultural perspectives. Honolulu, HI: University of Hawaii Press.

Oxford, R. L., \& Burry-Stock, J. A. (1995). Assessing the use of language learning strategies worldwide with the ESL/EFL version of the Strategy Inventory for Language Learning. System, 23(2) 153-175.

Oxford, R. L., \& Leaver, B. L. (1996). A synthesis of strategy instruction for foreign language learners. In R. L. Oxford (Ed.), Language learning strategies around the world: Cross-cultural perspectives (pp. 227-246). Honolulu, HI: University of Hawaii Press.

Oxford, R., Cho, Y., Leung, S., \& Kim, H-J. (2004). Effect of the presence and difficulty of task on strategy use: An exploratory study. International Review of Applied Linguistics, 42, 1-47. 
Ozeki, N. (2000). Listening strategy instruction for female EFL college students in Japan. Tokyo: Macmillan Language House.

Pressley, M. (1995). More about the development of self-regulation: Complex, longterm, and thoroughly social. Educational Psychologist, 30(4), 207-212.

Pressley, M. (2000). What should comprehension instruction be the instruction of? In M. L. Kamil, P. B. Mosenthal, P. D. Pearson, \& R. Barr (Eds.), Handbook of reading research: Volume III, (pp. 545-561). Mahwah, NJ: Erlbaum.

Ross, S., \& Rost, M. (1991). Learner use of strategies in interaction: Typology and teachability. Language Learning, 41(2), 235-273.

Rubin, J. (1975). What the "good language learner" can teach us. TESOL Quarterly, $9,41-51$.

Rubin, J. (2001). Language learner self-management. Journal of Asian Pacific Communication, 11(1), 25-37.

Rubin, J. (2003). Diary writing as a process: Simple, useful, powerful. Guidelines, 25(2), 10-14.

Rubin, J., \& Thompson, I. (1994). How to be a more successful language learner. Second edition. Boston: Heinle \& Heinle.

Schmitt, N. (2000). Vocabulary in language teaching. Cambridge: Cambridsge University Press.

Shen, H-J. (2003). The role of explicit instruction in ESL/EFL reading. Foreign Language Annals, 36(3), 424-433.

Stern, H. H. (1975). What can we learn from the good language learner? Canadian Modern Language Review, 31, 304-318.

Takeuchi, O. (2003). What can we learn from good language learners: A qualitative study in the Japanese foreign language context. System, 31, 385-392.

Thompson, I., \& Rubin, J. (1996). Can strategy instruction improve listening comprehension? Foreign Language Annals, 29(3), 331-342.

Vandergrift, L. (1997a). The comprehension strategies of second language (French) Listeners: A descriptive study. Foreign Language Annals, 30(3), 387-409.

Vandergrift, L. (1997b). The Cinderella of communication strategies: Reception strategies in interactive listening. Modern Language Journal, 81(4), 494505.

Vandergrift, L. (2003a). Orchestrating strategy use: Towards a model of the skilled L2 listener. Language Learning, 53, 461-494.

Vandergrift, L. (2003b). From prediction to reflection: Guiding students through the process of L2 listening. Canadian Modern Language Review, 59, 425-440.

Weaver, S. J., \& Cohen, A. D. (1997). Strategies-based instruction: A teachertraining manual. Minneapolis: Center for Advanced Research on Language Acquisition, University of Minnesota.

Wenden, A. L. (1991). Learner strategies for learner autonomy. London: PrenticeHall International.

Wenden, A. L. (2000). Learner development in language learning. Applied Linguistics, 23(1), 32-55.

Wharton, G. (2000). Language learning strategy use of bilingual foreign language learners in Singapore. Language Learning, 50(2), 203-243. 